\title{
A snapshot global survey on side effects of COVID-19 vaccines among healthcare professionals and armed forces with a focus on headache
}

\author{
Armando PERROTTA 1, Giuseppe BIONDI-ZOCCAI 2, 3, Wael SAADE ${ }^{4}$, Fabio MIRALDI ${ }^{4}$, Andrea MORELLI ${ }^{4}$, \\ Antonino G. MARULLO 2, Elena CAVARRETTA 2,3, Roberto CARNEVALE 2, 3, Elena DE FALCO 2,3, \\ Isotta CHIMENTI 2, 3, Sebastiano SCIARRETTA 1,2, Paola FRATI 1, 5, Mamas A. MAMAS 6, 7 , Sara CIARDI 8, \\ Luigi FRATI 1, 9, Giacomo FRATI 1, 2, Mariangela PERUZZI 3,4*
}

${ }^{1}$ IRCCS NEUROMED, Pozzilli, Isernia, Italy; ${ }^{2}$ Department of Medical-Surgical Sciences and Biotechnologies, Sapienza University, Latina, Italy; ${ }^{3}$ Mediterranea Cardiocentro, Naples, Italy; ${ }^{4}$ Department of Clinical, Internal Medicine, Anesthesiology and Cardiovascular Sciences, Sapienza University, Rome, Italy; ${ }^{5}$ Department of Anatomical Histological, Forensis and Orthopedic Sciences, Sapienza University, Rome, Italy; ${ }^{6}$ Keele Cardiovascular Research Group, Institutes of Applied Clinical Science and Primary Care and Health Sciences, University Hospital of North Midlands, Keele University, Stoke-on-Trent, UK; ${ }^{7}$ Department of Cardiology, Royal Stoke Hospital, Stoke-on-Trent, UK; ${ }^{8}$ Carabinieri Corps Health Service, Rome, Italy; ${ }^{9}$ Pasteur Institute, Rome, Italy

*Corresponding author: Mariangela Peruzzi, Department of Clinical, Internal Medicine, Anesthesiology and Cardiovascular Sciences, Sapienza University, Rome, Italy. E-mail: peruzzimari75@gmail.com.

\section{A B S T R A C T}

BACKGROUND: New messenger RNA (mRNA) and adenovirus-based vaccines (AdV) against Coronavirus disease 2019 (COVID-19) have entered large scale clinical trials. Since healthcare professionals (HCPs) and armed forces personnel (AFP) represent a high-risk category, they act as a suitable target population to investigate vaccine-related side effects, including headache, which has emerged as a common complaint. METHODS: We investigated the side-effects of COVID-19 vaccines among HCPs and AFP through a 38 closed-question international survey. The electronic link was distributed via e-mail or via Whatsapp to more than 500 contacts. Responses to the survey questions were analyzed with bivariate tests.

RESULTS: A total of 375 complete surveys have been analyzed. More than $88 \%$ received an mRNA vaccine and $11 \%$ received AdV first dose. A second dose of mRNA vaccine was administered in $76 \%$ of individuals. No severe adverse effects were reported, whereas moderate reactions and those lasting more than 1 day were more common with $\mathrm{AdV}(\mathrm{P}=0.002$ and $\mathrm{P}=0.024$ respectively $)$. Headache was commonly reported regardless of the vaccine type, but less frequently, with shorter duration and lower severity that usually experienced by participants, without significant difference irrespective of vaccine type.

CONCLUSIONS: Both mRNA and AdV COVID-19 vaccines were safe and well tolerated in a real-life subset of HCPs and AFP subjects.

(Cite this article as: Perrotta A, Biondi-Zoccai G, Saade W, Miraldi F, Morelli A, Marullo AG, et al. A snapshot global survey on side effects of COVID-19 vaccines among healthcare professionals and armed forces with a focus on headache. Panminerva Med 2021;63:324-31. DOI: 10.23736/ S0031-0808.21.04435-9)

KEY WORDS: COVID-19; Headache; Surveys and questionnaires; Vaccines.

$\mathrm{T}$ he severe acute respiratory syndrome Coronavirus 2 (SARS-CoV-2) emerged in China on December 2019 and has been declared a pandemic by the World Health Organization (WHO) on March 11, 2020. ${ }^{1}$ Due to its highly rapid spread joined with an high case fatality rate (CFR), the urgent need for vaccines prompted an international response, leading to inspired collaboration among key sectors of society, including academia, government, industry, regulators and the community with more than 100 candidate SARS$\mathrm{CoV}-2$ vaccines in development within the first 5 months of 2020.2, 3Vaccine development was initiated after the SARSCoV-2 genome was published on January 10, 2020. 


\section{COPYRIGHT $^{\circledR} 2021$ EDIZIONI MINERVA MEDICA}

Within less than 1 year, new messenger RNA (mRNA) vaccines, adenovirus based (AdV) or inactivated pathogen platform vaccines have entered large scale clinical trials for the first time ever with the aim to face this pandemic. ${ }^{4}$ The expedited vaccine development timeline resulting from the global effort in response to the COVID-19 pandemic has been unprecedented in terms of scale and speed, and it represents a fundamental change from the traditional vaccine elaboration paradigm. On March 17, 2020, Dr. Michael Witte administered to volunteers the first shot of an mRNA vaccine against the SARS-CoV-2 virus prepared by Moderna (Moderna Inc.; Cambridge, MA, USA). ${ }^{5}$ Messenger RNA vaccines have been developed specifically in order to be produced in a very short time to contain the pandemic. The RNA specific for a particular protein is brought into cells by virus-like particles or into liposomes or bound to nanoparticles and once the RNA is inside the infected cells, the cells use its genetic information to produce large amounts of the target protein.6,7 To date, mRNA COVID-19 vaccines have been the earliest available and widely used in mass vaccination campaigns.

Emerging data on safety (local and systemic reactions and adverse events) and immunogenicity from phase $1^{8}$ and ongoing phase $2 / 3^{9}$ studies revealed a low incidence of side effects with similar or even higher rates of SARSCoV-2 neutralizing titers than those from SARS-CoV-2 convalescent serum samples. The most frequently reported local reactions 7 days after the first and second dose of current available mRNA COVID-19 vaccine were pain at injection site (incidence between 58\% and 90\%) and, with a significantly lower percentage, redness and swelling (incidence $<10 \%$ ). The most common systemic events within 7 days of administration after each vaccine dose were headache (incidence between 25 to $52 \%$ ) and fatigue (incidence between 34 to $60 \%$ ), but also chills, muscle and joint pain were reported and overall they were more frequently described after the second dose. All adverse events were mild to moderate in severity. ${ }^{9}$

A few months later mRNA vaccine release, a recombinant adenovirus double dose version (ChAdOx1-nCov19-AstraZeneca/AZD1222 renamed Vaxzevria on March 31, 2021; AstraZenca, Cambridge, UK) also received emergency use authorization. This version of the vaccine is a replication-defective chimpanzee adenovirus construct that encodes for the SARS-CoV-2 Spike protein. ${ }^{10}$ This type of vaccine offers the advantages of being less expensive than mRNA vaccines and being stored and distributed at $2-8{ }^{\circ} \mathrm{C}$, making it particularly suitable for global distribution. Preclinical trials in pig models demonstrated a high antibody response. ${ }^{11}$ Accordingly, this vaccine moved on a clinical scenario in April 2020. Data on phase 1/2 studies revealed an acceptable safety profile and an high antibody response. ${ }^{10}$ However serious concerns recently emerged as unexpected possible side-effects following administration of ChAdOx1-nCov-19 (AstraZeneca).

Recent papers published on April 2021 reported few cases of unusual thrombotic events and thrombocytopenia after vaccination with the first dose of ChAdOx1-nCov-19 (AstraZeneca) which could result in the development of immune thrombotic thrombocytopenia mediated by platelet-activating antibodies against platelet factor 4 (PF4). 12,13 Available data suggest a slightly higher incidence of this adverse events in young people, especially women with a median age of 36 year. In contrast, the risks of severe disease associated with COVID-19 increases with age, with the youngest adults at lowest risk. To date, there are no reports of thrombosis/thrombocytopenia events following receipt of the second dose of ChAdOx1-nCov-19 (AstraZeneca) vaccine. A recent update of the European Medicines Agency (EMA) Pharmacovigilance Risk Assessment Committee (PRAC) reported that unusual blood clots with low blood platelets should be listed as very rare side effects of ChAdOx1-nCov-19 (AstraZeneca) vaccine. Nevertheless this data do not change the PRAC's recommendations with EMA confirming an overall positive benefit-risk ratio. ${ }^{14}$ Indeed, as of April 4, 2021, 169 cases of cerebral venous sinus thrombosis (CVST) and 53 cases of splanchnic vein thrombosis were reported to EudraVigilance, out of a total of around 34 million people had been vaccinated in the European Economic Area (EEA) and UK. Thus, not even these more recent data changed PRAC's recommendations.

In anticipation of a vaccination campaign that will involve a large part of the world population with consolidated and new vaccination technique, it is crucial to investigate the safety and tolerability of available COVID-19 vaccines in a real-life setting. Since HCPs are on the front lines in the fight against COVID-19 they were the first category of workers to be vaccinated starting from December 2020 and almost exclusively by mRNA vaccines and representing a suitable target population to investigate the new COVID-19 vaccines related adverse events in a reallife setting. Similarly, AFP has been prioritized in receiving COVID-19 vaccination due to the logistic role in distribution and administration of the vaccine to the general population, but almost exclusively by AdV based vaccine. Therefore, they represent another suitable population to collect preliminary data on AdV based vaccines, as well. 


\section{COPYRIGHT $^{\circledR} 2021$ EDIZIONI MINERVA MEDICA}

PERROTTA

SIDE EFFECTS OF COVID-19 VACCINES

Furthermore, since headache was the most reported COVID-19 vaccine systemic adverse event and primary headaches are worldwide recognized as highly frequent in the general population $(10-15 \%$ incidence in western countries), ${ }^{15}$ we investigated if subjects with recurrent headache could be more prone to develop headache as an adverse event after COVID-19 vaccination. Accordingly we investigated a series of solicited adverse events of COVID-19 vaccines (based on the most frequently described in clinical trials) among HCPs and AFP belonging to different international institutions in order to determine the impact in terms of safety profile of the different available vaccines in a real-life-medicine setting.

\section{Materials and methods}

This is a online survey study, based on an email observational descriptive cross-sectional design. Specifically, an online survey form was sent to HCPs and AFP involved in their local vaccination campaigns worldwide (Supplementary Digital Material 1: Supplementary Table I), totaling over 500 subjects retrieved using the authors' professional interpersonal relationships.

The survey was developed with the Google Forms application (Alphabet; Mountain View, CA, USA) to conduct automated surveys and included a questionnaire which contained 38 questions on demographics, professional experience, presence and frequency of headache, vaccination details, solicited (based on those reported in previous studies) and unsolicited adverse events complained within 7 days after the administration of the first and second dose of the COVID-19 vaccine. As local reaction we included pain and/or paresthesia and swelling at the injection site, as systemic ones headache, asthenia, myalgia, fever, insomnia, nausea, urticaria, lymphadenopathia. Furthermore, the questionnaire included questions on frequency, duration, intensity and need for treatment for headache within 7 days and between 7 and 14 days after the administration of the first and second dose of the COVID-19 vaccine. Clinical characteristics of headache was collected according to the International Classification of Headache Disorders Third Edition ${ }^{16}$ and oriented to identify primary headache including migraine and tension-type headache. When applicable the intensity of the side effects was graded as follows: mild, does not interfere with activity; moderate, interferes with activity; severe, prevents activity. The question types were single-choice, multiplechoice and open-ended. Data were collected from January to April 2021. Before completion of the questionnaires, participants were informed about the aims of the study and that the results would be used for research purposes only and that the answers will be strictly confidential.

\section{Statistical analysis}

Categorical variables are reported as count (\%), and were compared with Fisher's exact test. No formal size computation was performed, but we deemed adequate a sample of at least 200 participants to ensure representativeness and sufficiently small $95 \%$ confidence intervals. Statistical significance was set at the 2-tailed 0.05 level, without multiplicity adjustment. Computations were performed with Stata 13 (StataCorp; College Station, TX, USA).

\section{Results}

A total of 375 vaccinated subjects completed the survey 7-14 days after being injected with mRNA vaccines (Pfizer-BioNTech in 336 [89.6\%]; Pfizer Inc., Brooklyn, NY, USA; BioNTech SE, Mainz, Germany), including $285(76.0 \%)$ receiving both doses, and 38 with AdV-based vaccines (ChAdOx1 Astra-Zeneca-Oxford in 35 [92.1\%]) (Table I). Data were reported according to the type and dose number of vaccines received.

After the first dose of mRNA COVID-19 vaccine 221 (65.6\%) out of 337 participants experienced mild to moderate side-effects, with a large prevalence of mild ones (Figure 1, Table II). After the first dose of AdV vaccine 31 $(81.6 \%)$ out of 38 participants experienced mild to moderate side-effects, with a large prevalence of mild ones. No participant reported severe local or systemic reactions, irrespective of vaccine. A large majority of participants reported local and systemic side-effects resolved in no more than 24 hours after both the first dose.

\section{Adverse effects}

When the local side effects after the first and second dose of mRNA vaccine were considered, the most common were pain and/or paresthesia in the injection side (Supplementary Digital Material 2: Supplementary Table II). The same applied to the first dose of AdV vaccine (Figure 2). The most commonly reported systemic events within 7 days after the two doses of mRNA vaccine were headache, asthenia and myalgia, which were significantly most often reported after the second dose than after the first one. In general, all reported systemic side-effects, including fever, insomnia, nausea, lymphadenopathia, urticaria were more frequent after the second dose than the first dose of mRNA 


\section{COPYRIGHT $^{\odot} 2021$ EDIZIONI MINERVA MEDICA}

SIDE EFFECTS OF COVID-19 VACCINES

PERROTTA

TABLE I.-Characteristics of the study population.

\begin{tabular}{|c|c|c|c|c|c|c|}
\hline Features & & Total vaccinated & $\begin{array}{l}\text { mRNA first } \\
\text { dose only }\end{array}$ & $\begin{array}{l}\text { mRNA } \\
\text { first and } \\
\text { second dose }\end{array}$ & $\begin{array}{l}\text { AdV first } \\
\text { dose only }\end{array}$ & $\mathrm{P}$ \\
\hline Participants & & 375 & 48 & 285 & 38 & - \\
\hline Female sex & Female & $173(46.1 \%)$ & $18(37.5)$ & $141(48.8 \%)$ & $14(36.8 \%)$ & 0.175 \\
\hline \multirow[t]{6}{*}{ Age group } & $18-30$ & $51(13.6 \%)$ & $5(10.4 \%)$ & $39(13.5 \%)$ & $7(18.4 \%)$ & 0.388 \\
\hline & $31-40$ & $101(26.9 \%)$ & $12(25.0 \%)$ & $77(26.6 \%)$ & $12(31.6 \%)$ & \\
\hline & $41-50$ & $138(36.8 \%)$ & $18(37.5 \%)$ & $112(38.8 \%)$ & $8(21.1 \%)$ & \\
\hline & $51-60$ & $57(15.2 \%)$ & $9(18.8 \%)$ & $40(13.8 \%)$ & $8(21.1 \%)$ & \\
\hline & $61-70$ & $27(7.2 \%)$ & $3(6.3 \%)$ & $21(7.3 \%)$ & $3(7.9 \%)$ & \\
\hline & $>71$ & $1(0.3 \%)$ & $1(2.1 \%)$ & 0 & 0 & \\
\hline \multirow[t]{3}{*}{ Profile } & Physicians & $292(77.9 \%)$ & $44(91.7 \%)$ & $235(81.3 \%)$ & $10(28.6 \%)$ & $<0.001$ \\
\hline & Nurse & $31(8.3 \%)$ & 0 & $27(9.3 \%)$ & $4(11.4 \%)$ & \\
\hline & Armed forced personnel & $52(77.9 \%)$ & $4(8.3 \%)$ & $27(9.3 \%)$ & $21(60.0 \%)$ & \\
\hline \multirow[t]{4}{*}{ Area } & Asia & $10(2.7 \%)$ & $1(2.1 \%)$ & $7(2.4 \%)$ & $1(2.9 \%)$ & 0.430 \\
\hline & Central and South America & $4(1.1 \%)$ & 0 & $1(0.4 \%)$ & $1(2.9 \%)$ & \\
\hline & Europe & $354(92.3 \%)$ & $45(95.7 \%)$ & $267(92.4 \%)$ & $33(94.3 \%)$ & \\
\hline & North America & $15(4.0 \%)$ & $1(2.1 \%)$ & $14(4.8 \%)$ & 0 & \\
\hline \multirow{6}{*}{$\begin{array}{l}\text { Have you ever been infected } \\
\text { with SARS-CoV-2? }\end{array}$} & Yes, I was admitted & $1(0.3 \%)$ & 0 & $1(0.4 \%)$ & 0 & 0.029 \\
\hline & Yes, with non-severe symptoms & $16(4.3 \%)$ & $3(6.4 \%)$ & $12(4.2 \%)$ & $1(2.9 \%)$ & \\
\hline & Yes, asymptomatic & $7(1.9 \%)$ & 0 & $7(2.4 \%)$ & 0 & \\
\hline & No, I do not even have antibodies & $146(38.9 \%)$ & $23(48.9 \%)$ & $113(39.1 \%)$ & $9(25.7 \%)$ & \\
\hline & No, I was vaccinated & $133(35.5 \%)$ & $7(14.9 \%)$ & $108(37.4 \%)$ & $18(51.4 \%)$ & \\
\hline & $\begin{array}{l}\text { No, I have never done the antibody } \\
\text { test }\end{array}$ & $72(19.2 \%)$ & $14(29.8 \%)$ & $48(16.6 \%)$ & $7(20.0 \%)$ & \\
\hline \multirow[t]{3}{*}{ Comorbidities } & $\begin{array}{l}\text { Autoimmune or inflammatory } \\
\text { disease }\end{array}$ & $27(7.2 \%)$ & $3(6.4 \%)$ & $23(8.0 \%)$ & $1(2.9 \%)$ & 0.680 \\
\hline & Cardiopulmonary disease & $42(11.2 \%)$ & $6(12.8 \%)$ & $29(10.0 \%)$ & $5(14.3 \%)$ & 0.584 \\
\hline & Other disease & $32(8.5 \%)$ & $6(12.8 \%)$ & $22(7.6 \%)$ & $4(11.4 \%)$ & 0.342 \\
\hline $\begin{array}{l}\text { Did you receive the } \\
\text { influenza vaccine in } 2020 ?\end{array}$ & & $278(74.1 \%)$ & $33(70.2 \%)$ & $232(80.3 \%)$ & $10(28.6 \%)$ & $<0.001$ \\
\hline $\begin{array}{l}\text { Would you recommend the } \\
\text { COVID-19 vaccine to } \\
\text { your patients }\end{array}$ & & $371(98.9 \%)$ & $46(97.8 \%)$ & $285(100 \%)$ & $35(100 \%)$ & 0.223 \\
\hline
\end{tabular}

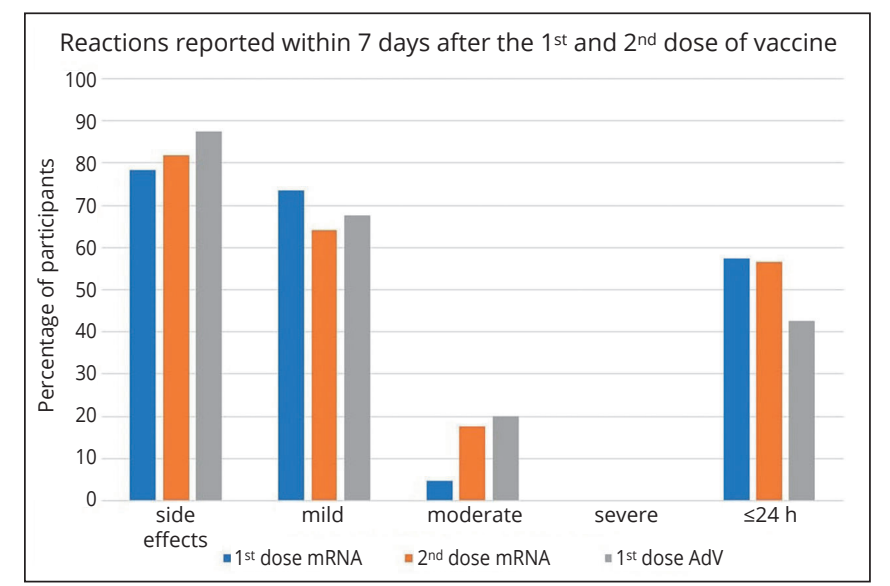

Figure 1.-Adverse effects reported within 7 days after the first and second dose of COVID-19 vaccine in a population of healthcare workers and armed forces personnel.

Data are expressed in percentage. The severity of the adverse events was assessed according to the following scale: mild, does not interfere with activity; moderate, interferes with activity; severe, prevents daily activity. vaccine. The most commonly reported systemic events within 7 days after the first dose of AdV vaccine were headache, myalgia, fever, and asthenia. All systemic side effects reported within 7 days after the first dose of Adv vaccine were more frequently observed when compared to both the first and second dose of mRNA vaccine.

\section{Headache}

Two hundred seventeen (57.9\%) out of the 375 participants had previously suffered from headache in their lifetime, $115(63.3 \%)$ were females, and $178(58.4 \%)$ reported having suffered from headache in the last 12 months, with a higher female prevalence $(\mathrm{P}<0.001)$ (Supplementary Digital Material 3: Supplementary Table III, Supplementary Table IV). Among those who previously suffered from headache, most reported 1 to 6 average episodes of headaches per month, of mild to moderate intensity, and less than 1-day duration. Pressing or tightening pain was the most common reported symptom, with non-steroidal anti- 


\section{COPYRIGHT ${ }^{\odot} 2021$ EDIZIONI MINERVA MEDICA}

PERROTTA

SIDE EFFECTS OF COVID-19 VACCINES

TABLE II.-Details of first COVID-19 vaccine.

\begin{tabular}{|c|c|c|c|c|c|c|}
\hline Features & & Total vaccinated & mRNA first dose & mRNA second & AdV first dose & $\mathrm{P}$ \\
\hline Participants & & 375 & 48 & 285 & 38 & - \\
\hline \multirow{4}{*}{$\begin{array}{l}\text { Have you had adverse effects } \\
\text { after the first COVID-19 } \\
\text { vaccine? }\end{array}$} & No & $123(32.8 \%)$ & $13(27.8 \%)$ & $108(37.9 \%)$ & $7(18.4 \%)$ & 0.002 \\
\hline & Mild reaction & $230(61.3 \%)$ & $31(66.0 \%)$ & $176(60.9 \%)$ & $23(60.5 \%)$ & \\
\hline & Moderate reaction & $22(5.9 \%)$ & $3(6.4 \%)$ & $11(3.8 \%)$ & $8(21.1 \%)$ & \\
\hline & Severe reaction & 0 & 0 & 0 & 0 & \\
\hline \multirow{10}{*}{$\begin{array}{l}\text { Main adverse effects after the } \\
\text { first COVID-19 vaccine }\end{array}$} & Fatigue & $47(15.9 \%)$ & $4(11.1 \%)$ & $35(15.5 \%)$ & $7(21.9 \%)$ & 0.521 \\
\hline & Fever & $24(8.1 \%)$ & $1(2.8 \%)$ & $11(4.9 \%)$ & $12(37.5 \%)$ & $<0.001$ \\
\hline & Headache & $67(22.6 \%)$ & $9(25.0 \%)$ & $45(19.9 \%)$ & $13(40.6 \%)$ & 0.102 \\
\hline & Insomnia & $5(1.7 \%)$ & 0 & $3(1.3 \%)$ & $2(6.3 \%)$ & 0.165 \\
\hline & Lymphadenopathy & $3(1.0 \%)$ & 0 & $3(1.3 \%)$ & 0 & 1 \\
\hline & Muscle or joint pain & $23(7.8 \%)$ & $4(11.1 \%)$ & $13(5.8 \%)$ & $5(15.6 \%)$ & 0.149 \\
\hline & Nausea or vomiting & $7(2.4 \%)$ & 0 & $4(1.8 \%)$ & $3(9.4 \%)$ & 0.067 \\
\hline & $\begin{array}{l}\text { Pain or paresthesia at injection } \\
\text { site }\end{array}$ & $237(80.1 \%)$ & $29(80.6 \%)$ & $187(100 \%)$ & $18(56.3 \%)$ & $<0.001$ \\
\hline & $\begin{array}{l}\text { Swelling or redness at injection } \\
\text { site }\end{array}$ & $34(11.5 \%)$ & $6(16.7 \%)$ & $25(11.1 \%)$ & $3(9.4 \%)$ & 0.679 \\
\hline & Tachycardia & $10(3.4 \%)$ & $4(11.1 \%)$ & $5(2.2 \%)$ & $1(3.1 \%)$ & 0.048 \\
\hline \multirow{6}{*}{$\begin{array}{l}\text { Adverse effect duration after the } \\
\text { first COVID-19 vaccine }\end{array}$} & $<15$ minutes & $14(4.8 \%)$ & 0 & $13(5.8 \%)$ & $1(3.1 \%)$ & 0.024 \\
\hline & $15-60$ minutes & $17(5.8 \%)$ & $1(2.8 \%)$ & $14(6.2 \%)$ & $1(3.1 \%)$ & \\
\hline & $2-12$ hours & $24(8.1 \%)$ & $2(5.6 \%$ & $20(8.9 \%)$ & $2(6.3 \%)$ & \\
\hline & 13-24 hours & $153(51.9 \%)$ & $18(50.0 \%)$ & $123(54.7 \%)$ & $11(34.4 \%)$ & \\
\hline & 2-6 days & $82(27.8 \%)$ & $13(36.1 \%)$ & $52(23.1 \%$ & $17(53.1 \%)$ & \\
\hline & $\geq 1$ week & $5(1.7 \%)$ & $2(5.6 \%)$ & $3(1.3 \%)$ & 0 & \\
\hline
\end{tabular}

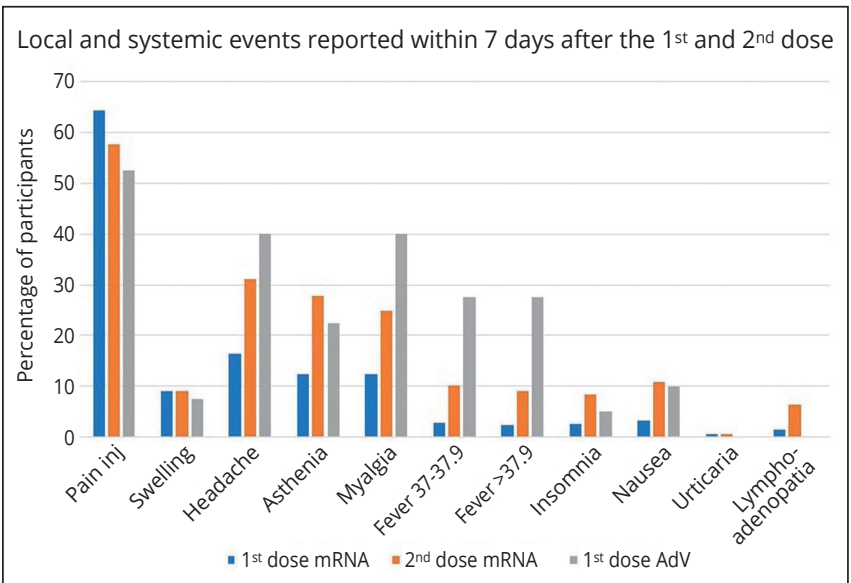

Figure 2.- Relative distribution of local and systemic adverse effects reported within 7 days after the first and second dose of COVID-19 vaccine in a population of healthcare workers and armed forces personnel. Data are expressed in percentage.

inflammatory drugs (NSAID) and paracetamol being most commonly used (Figure 3, 4).

Focusing on the relationship between vaccination and headache, we observed that $84(22.4 \%)$ participants reported headache within 14 days of vaccination, with a similar rate, severity and duration irrespective of vaccine type (all $\mathrm{P}>0.05$ ) (Table III). Considering the proportion of participants suffering with headache, $20(14.5 \%)$ out of

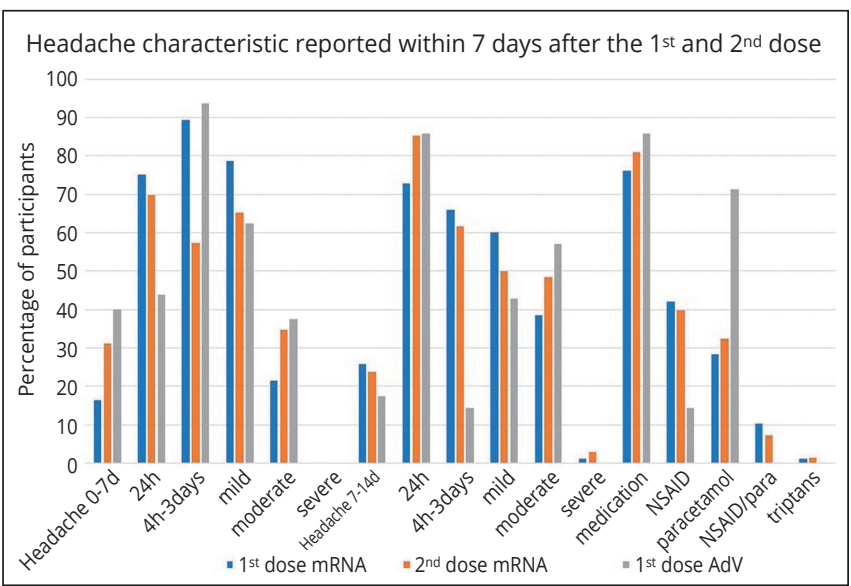

Figure 3.-Headache characteristic reported within 14 days after first ans second dose of COVID-19 vaccine in a population of healthcare workers and armed forces personnel.

Data are expressed in percentage.

137 experiencing side effects, complained headache as a side effect 7 days after the first dose of both vaccine types while $15(8.7 \%)$ out of 171 suffering with headache who received the second dose of mRNA vaccine experienced headache as a side effect 7 days after the second dose. Both after the first and the second dose the incidence of headache within 7days after the vaccine injection was lower compared to the whole population studied. 


\section{COPYRIGHT $^{\circledR} 2021$ EDIZIONI MINERVA MEDICA}

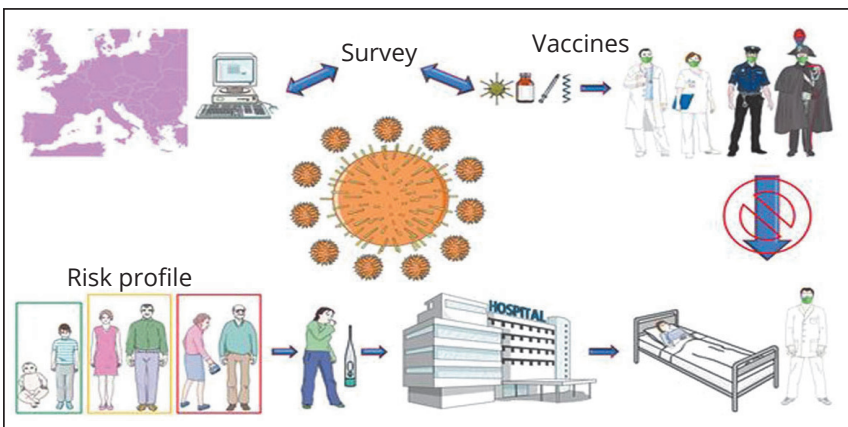

Figure 4.-An overview of the global pandemic with the main professional figures involved in the survey.

On the contrary, in the subgroup of the headache prone, the incidence of headache in the 7-14 days after the the first and the second dose was higher when compared to the whole population studied, 70 (31.2\%) out of 224 suffering with headache who received the first dose of the vaccines and $56(32.7 \%)$ out of 171 suffering with headache who received the second dose of the mRNA vaccine respectively.

\section{Discussion}

The outbreak of severe acute respiratory syndrome Coronavirus 2 (SARS-CoV-2), named Coronavirus disease 2019 (COVID-19) has evolved into a global pandemic. Control measures such as the use of masks, physical distancing, contact tracing and selective isolation have partially limited the transmission of the virus when strictly applied; however, these measures have not been sufficient to stop the spread of COVID-19. Development of an effective vaccine to reduce the morbidity and mortality associated with $\mathrm{CO}$ VID-19 was the main goal of many countries. As of February 2021 , there were 73 vaccines with various platforms in clinical trials worldwide ${ }^{17}$ and within 12 months after the emergence of this novel pandemic, new mRNA vaccines, AdV- based vaccines or inactivated pathogen platform vaccines have entered large scale clinical trials with the aim to face this pandemic. DNA- and RNA-based platforms, had the greatest potential in terms of speed development, since they do not require culture or fermentation. Both the BioNTech-Pfizer and Moderna vaccinations use the mRNA platform which is incapable of causing the disease and is metabolized in the cytoplasm without entering the nucleus, thus not interacting with human DNA. Emerging data on safety and immunogenicity from phase $1^{8}$ and ongoing phase $2 / 3^{9}$ studies revealed a low incidence of side effects for both platforms. Mild to moderate adverse reactions were reported for both mRNA vaccines (injection site pain, fatigue, chills and fever) and are usually responsive to antipyretic or pain medications, while serious adverse events were rare for both vaccines..$^{18}$ On the other side, the ChAdOx1-nCov-19 (AstraZeneca) vaccine use a viral vector (Adenovirus) to carry the genetic sequence. Adenovirus delivers the target gene sequence without being able to replicate or causing disease. As mentioned above, recent scientific literature reported severe adverse effects after the first dose of the ChAdOx1-nCov-19 (AstraZeneca) vaccine $^{12,13}$ in particular thrombotic events especially in young adult females. The EMA's Pharmacovigilance Risk Assess-

\section{TABLE III.-Features of headache after COVID-19 vaccination.}

\begin{tabular}{|c|c|c|c|c|c|c|}
\hline \multicolumn{2}{|l|}{ Features } & Total vaccinated & mRNA first dose & mRNA second & AdV first dose & $\mathrm{P}$ \\
\hline \multicolumn{2}{|l|}{ Participants } & 375 & 48 & 285 & 38 & - \\
\hline \multicolumn{2}{|l|}{$\begin{array}{l}\text { Headache within } 14 \text { days after } \\
\text { first COVID-19 vaccine }\end{array}$} & $84(22.4 \%)$ & $14(29.2 \%)$ & $63(22.1 \%)$ & $7(18.4 \%)$ & 0.440 \\
\hline Headache duration after the first & $<4$ hours & $25(29.8 \%)$ & $2(14.3 \%)$ & $22(34.9 \%)$ & $1(16.7 \%)$ & 0.825 \\
\hline \multirow{3}{*}{ COVID-19 vaccine } & 4-24 hours & $40(47.6 \%)$ & $8(57.1 \%)$ & $28(44.4 \%)$ & $3(50.0 \%)$ & \\
\hline & 2-3 days & $15(17.9 \%)$ & $3(21.4 \%)$ & $10(15.8 \%)$ & $2(33.3 \%)$ & \\
\hline & $>3$ days & $4(4.8 \%)$ & $1(7.1 \%)$ & $3(4.8 \%)$ & 0 & \\
\hline \multirow[t]{3}{*}{ Intensity } & Mild & $52(57.1 \%)$ & $9(64.3 \%)$ & $34(53.9 \%)$ & $2(33.3 \%)$ & 0.162 \\
\hline & Moderate & $38(41.8 \%)$ & $5(35.7 \%)$ & $28(44.4 \%)$ & $4(66.7 \%)$ & \\
\hline & Severe & $1(1.1 \%)$ & 0 & $1(4.8 \%)$ & 0 & \\
\hline \multicolumn{2}{|l|}{$\begin{array}{l}\text { Headache within } 14 \text { days after } \\
\text { second COVID-19 vaccine }\end{array}$} & $73(21.5 \%)$ & - & $70(25.4 \%)$ & - & - \\
\hline Headache duration after the first & $<4$ hours & $19(26.4 \%)$ & - & $18(26.5 \%)$ & - & - \\
\hline \multirow[t]{3}{*}{ COVID-19 vaccine } & 4-24 hours & $42(58.3 \%)$ & - & $39(57.4 \%)$ & - & - \\
\hline & 2-3 days & $9(12.5 \%)$ & - & $9(13.2 \%)$ & - & - \\
\hline & $>3$ days & $282.8 \%)$ & - & $2(2.9 \%)$ & - & - \\
\hline \multirow[t]{3}{*}{ Intensity } & Mild & $35(48.6 \%)$ & - & $36(51.4 \%)$ & - & - \\
\hline & Moderate & $35(48.6 \%)$ & - & $32(45.7 \%)$ & - & - \\
\hline & Severe & $2(2.8 \%$ & - & $2(2.9 \%)$ & - & - \\
\hline
\end{tabular}




\section{COPYRIGHT $^{\circledR} 2021$ EDIZIONI MINERVA MEDICA}

ment Committee (PRAC) update still reaffirmed that the benefits of the vaccine continue to outweigh the risks for people who receive it. The vaccine is effective in preventing COVID-19 and reducing hospitalizations and deaths. HCWs have been identified by the Advisory Committee on Immunization Practices (ACIP) as a priority group for COVID-19 vaccination ${ }^{19}$ since this category of workers is on the front lines in the fight against COVID-19. Similarly, in several countries AFP has been prioritized due to the logistic support offered to the vaccination campaign.

The total proportion of subjects who reported any side effect/adverse event (local or systemic) in the sample of HCWs and AFP who completed the survey after both doses of COVID-19 vaccine is between almost $80 \%$ of the first dose of mRNA vaccine and almost $90 \%$ of the first dose of the AdV-based vaccine, with the second dose of the mRNA vaccine in the middle. The reported side effects were mild in the majority, but the proportion of moderate ones rose from $5 \%$ for the first dose of mRNA vaccines to $17 \%$ of the second dose and to the $20 \%$ of the first dose of the AdV vaccine. For none of the selected vaccines severe adverse events were detected. In line with the higher prevalence of side effects after AdV vaccine, we observed that the duration of the side effects, regardless of the severity, was limited to the day of onset in almost $60 \%$ of the cases after the mRNA vaccine, but only in $40 \%$ of those who received the AdV vaccine.

Notably, pain and/or paresthesia in the injection side was the most common local reaction, reported by almost $65 \%$ of the participants after the first dose and by almost $60 \%$ after the second dose of the mRNA vaccine, but less frequently, (almost 55\%), after the first dose of AdV vaccine. Swelling at the injection site was the second most reported local reaction, but significantly less frequently observed than the previous one. These data are in line with what has been observed in the ongoing phase $2 / 3$ studies. 9,20

Overall, for each vaccine type and dose number, the solicited systemic adverse events, including headache, asthenia, myalgia, fever, insomnia, urticaria, nausea and lymphadenopathy, were always less frequently reported compared to the most frequent local reaction (pain at the injection side). However, we observed an increasing prevalence between the first to second dose of the mRNA vaccine and from the latter to the first dose of the AdV vaccine, in particular for headache, asthenia, myalgia and fever.

In addition, headache, asthenia and myalgia were the most reported systemic adverse events after both the first and second dose of the mRNA vaccine and all of them were more common and severe after the second dose than the first. These data resemble what has been observed in larger samples ${ }^{9}$ including the higher incidence after the second dose of the mRNA vaccine. Headache, myalgia and fever, in particular, were more frequently reported after the first dose of the AdV vaccine compared to the first and second dose of mRNA vaccine. However, for all these adverse events, we observed a lower incidence when compared with that observed in clinical trials. 9,21

When we considered headache in detail, we observed that its incidence within 7 days after both the first and the second dose of the mRNA vaccine and the first dose of the $\mathrm{AdV}$ vaccine was lower than that usually reported in the observed population as well as of less severity and duration. In addition, also in the case of headache, we observed a higher incidence and severity after the second dose of the mRNA vaccine compared to the first one and between the first dose of the AdV vaccine and the second dose of the mRNA vaccine.

Interestingly, the frequency of headache within 7-14 days after the two doses of the mRNA vaccine and the first of the AdV vaccine is also lower than that usually observed in the studied population, without differences between vaccine types, dose number and with a comparable duration, severity and medication intake than that usually declared by the participants.

In the participants usually suffering from headache: 1) the incidence of adverse events within 7 days after the first dose of both vaccine types and the second dose of the mRNA vaccine is in line with the whole population studied; 2) the incidence of headache as an adverse event is lower than that observed in the whole population studied; and 3) as expected from headache sufferers, within 7-14 days after both the vaccine doses the incidence of headache was higher than that observed in the whole population studied.

Accordingly, our data confirm after both the first and second dose of anti-COVID mRNA vaccine an higher incidence of local reactions, however of short duration and slight intensity; a low incidence of systemic adverse events, in the majority of mild severity and duration not exceeding 24hours; a lower incidence of systemic adverse events than that observed in phase $2 / 3$ studies; an higher incidence of systemic adverse events after the second dose compared to the first one of mRNA vaccine.

\section{Limitations of the study}

In spite of the limitation due to the low sample size of the AdV-based vaccine group, we observed a comparable incidence of local side effects, but an higher incidence of 


\section{COPYRIGHT $^{(\odot)} 2021$ EDIZIONI MINERVA MEDICA}

systemic side effects, including headache, myalgia and fever compared to the mRNA vaccine. Furthermore we observed a higher incidence of adverse events of moderate severity and also a lower proportion of those with a duration non exceeding 24 hours. Concerning the headache, it represents one of the most frequently observed adverse events within 7 days after both first and the second dose of the mRNA vaccine and even more after first dose of the AdV vaccine. However, the headache frequency is lower than that usually observed in the studied population. Furthermore, in the subgroup of the headache sufferers the incidence of the headache as an adverse event within 7 days after the vaccination is lower than that usually observed in the whole population studied and the incidence of headache within 7-14 days from vaccination is in line with declared as usual by participants.

\section{Conclusions}

In conclusions, these data support the evidence that the vaccination is safe and well tolerated in a real-life subset of HCWs and AFP and that it does not worsen headache incidence or duration in headache sufferers.

\section{References}

1. Biondi Zoccai G, Landoni G, Carnevale R, Cavarretta E, Sciarretta S, Frati G. SARS-CoV-2 and COVID-19: facing the pandemic together as citizens and cardiovascular practitioners. Minerva Cardioangiol 2020;68:61-4.

2. McIntyre P, Joo YJ, Chiu C, Flanagan K, Macartney K. COVID-19 vaccines - are we there yet? Aust Prescr 2021;44:19-25.

3. Saglietto A, D'Ascenzo F, Zoccai GB, De Ferrari GM. COVID-19 in Europe: the Italian lesson. Lancet 2020;395:1110-1.

4. Zhao J, Zhao S, Ou J, Zhang J, Lan W, Guan W, et al. COVID-19: Coronavirus Vaccine Development Updates. Front Immunol 2020;11:602256.

5. Baden LR, El Sahly HM, Essink B, Kotloff K, Frey S, Novak R, et al.; COVE Study Group. Efficacy and Safety of the mRNA-1273 SARSCoV-2 Vaccine. N Engl J Med 2021;384:403-16.

6. Wrapp D, Wang N, Corbett KS, Goldsmith JA, Hsieh CL, Abiona O, et al. Cryo-EM structure of the 2019-nCoV spike in the prefusion conformation. Science 2020;367:1260-3.

7. Pardi N, Tuyishime S, Muramatsu H, Kariko K, Mui BL, Tam YK, et al. Expression kinetics of nucleoside-modified mRNA delivered in lipid nanoparticles to mice by various routes. J Control Release $2015 ; 217: 345-51$.

8. Walsh EE, Frenck RW Jr, Falsey AR, Kitchin N, Absalon J, Gurtman A, et al. Safety and immunogenicity of two RNA-based Covid-19 vaccine candidates. N Engl J Med 2020;383:2439-50.

9. Polack FP, Thomas SJ, Kitchin N, Absalon J, Gurtman A, Lockhart S, et al.; C4591001 Clinical Trial Group. Safety and Efficacy of the BNT162b2 mRNA Covid-19 Vaccine. N Engl J Med 2020;383:2603-15.

10. Folegatti PM, Ewer KJ, Aley PK, Angus B, Becker S, Belij-Rammerstorfer S, et al.; Oxford COVID Vaccine Trial Group. Safety and immunogenicity of the ChAdOx $1 \mathrm{nCoV}-19$ vaccine against SARS-CoV-2: a preliminary report of a phase $1 / 2$, single-blind, randomised controlled trial. Lancet 2020;396:467-78.

11. Graham SP, McLean RK, Spencer AJ, Belij-Rammerstorfer S, Wright D, Ulaszewska M, et al. Evaluation of the immunogenicity of prime-boost vaccination with the replication-deficient viral vectored COVID-19 vaccine candidate ChAdOx1 nCoV-19. NPJ Vaccines 2020;5:69.

12. Greinacher A, Thiele T, Warkentin TE, Weisser K, Kyrle PA, Eichinger S. Thrombotic Thrombocytopenia after ChAdOx1 nCov-19 Vaccination. N Engl J Med 2021;384:2092-101.

13. Schultz NH, Sørvoll IH, Michelsen AE, Munthe LA, Lund-Johansen F, Ahlen MT, et al. Thrombosis and Thrombocytopenia after ChAdOx 1 nCoV-19 Vaccination. N Engl J Med 2021;384:2124-30.

14. AstraZenca. AIFA; 2021 [Internet]. Available from: https://www. aifa.gov.it/documents/20142/1289823/2021.04.07 COVID19\%20AstraZeneca_EN.pdf [cited 2021, Jul 6].

15. GBD 2016 Headache Collaborators. Global, regional, and national burden of migraine and tension-type headache, 1990-2016: a systematic analysis for the Global Burden of Disease Study 2016. Lancet Neurol 2018;954-76.

16. Headache Classification Committee of the International Headache Society. The international classification of headache disorders, 3rd edition. Cephalalgia. 2018;38:1-211

17. The COVID-19 candidate vaccine landscape and tracker. World Health Organization; 2021 [Internet]. Available from: https://www.who. int/publications $/ \mathrm{m} /$ item/draftlandscape-of-covid-19-candidate-vaccines [cited 2021, Jul 6].

18. Wu CP, Adhi F, Culver D. Vaccination for COVID-19: is it important and what should you know about it? Cleve Clin J Med 2021. [Epub ahead of print]

19. Dooling K, McClung N, Chamberland M, Marin M, Wallace M, Bell BP, et al. The Advisory Committee on Immunization Practices' Interim Recommendation for Allocating Initial Supplies of COVID-19 Vaccine - United States, 2020. MMWR Morb Mortal Wkly Rep 2020;69:1857-9.

20. A phase III randomized, double-blind, placebo-controlled multicenter study in adults to determine the safety, efficacy, and immunogenicity of AZD1222, a non-replicating ChAdOx1 vector vaccine, for the prevention of COVID-19. ClinicalTrials.gov; 2020 [Internet]. Available from: https://clinicaltrials.gov/ct2/show/NCT04516746?term=astrazene ca\&cond $=$ covid-19\&draw=2\&rank=1 [cited 2021, Jul 6].

21. Voysey M, Clemens SA, Madhi SA, Weckx LY, Folegatti PM, Aley PK, et al.; Oxford COVID Vaccine Trial Group. Safety and efficacy of the ChAdOx1 nCoV-19 vaccine (AZD1222) against SARS-CoV-2: an interim analysis of four randomised controlled trials in Brazil, South Africa, and the UK. Lancet 2021;397:99-111.

Conflicts of interest.-Giuseppe Biondi-Zoccai has consulted for Cardionovum, InnovHeart, Meditrial, Opsens Medical, and Replycare, Armando Perrotta has consulted for Eli Lilly and Novartis.

Authors' contributions.-Armando Perrotta, Giuseppe Biondi-Zoccai, Giacomo Frati and Mariangela Peruzzi have given substantial contributions to study design and manuscript writing, Fabio Miraldi, Andrea Morelli, Antonino G. Marullo, Elena Cavarretta, Roberto Carnevale, Elena De Falco, Isotta Chimenti, Sebastiano Sciarretta, Paola Frati, Mamas A. Mamas, Sara Ciardi and Luigi Frati to manuscript critical revision for important intellectual content. All authors read and approved the final version of the manuscript.

History.-Manuscript accepted: May 17, 2021. - Manuscript received: May 5, 2021.

Supplementary data.-For supplementary materials, please see the HTML version of this article at www.minervamedica.it 